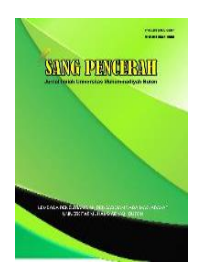

SANG PENCERAH

Volume 5 Issue 2, 2019

P-ISSN : 2528-360X, E-ISSN : 2621-6159

Website: https://www.jurnal-umbuton.ac.id/index.php/Pencerah

\title{
Pengaruh Program Bantuan Stimulan Perumahan Swadaya (BSPS) Pada Masyarakat di Kelurahan Lowulowu Kecamatan Lealea Kota Baubau
}

\author{
1 Kuflia Muak Hara
}

\begin{abstract}
The house renovation program is one of the programs of the government in an effort to provide protection to poor families in order to improve the level of welfare of poor families. This program is carried out in the form of providing building materials along with builders and technicians to build or renovate homes that are not livable and do not meet the heal th requirements of being livable. This study aims to address the research problem of the socio-economic and environmental impacts of a government program called Self-Help Housing Stimulant Assistance (BSPS) for low-income people in the City of Baubau especially in Sub-Lowulowu. The BSPS program provides a fairly good change and impact. The BSPS program improves the quality of residents' homes and increases welfare.

Keywords: BSPS Program; Program Impact; Social Economy Impact; Environmental Impact; Residential house
\end{abstract}

\begin{abstract}
Abstrak
Program bedah rumah merupakan salah satu program dari pemerintah dalam upaya untuk memberikan perlindungan pada keluarga miskin guna meningkatkan tingkat kesejahteraan keluarga miskin tersebut. Program ini dilaksanakan dalam bentuk pemberian bantuan bahan bangunan beserta tukang dan tenaga teknisi untuk membangun atau merenovasi rumah yang tidak layak huni dan tidak memenuhi syarat kesehatan menjadi rumah yang layak huni. Penelitian ini bertujuan untuk menjawab masalah penelitian tentang dampak sosial ekonomi dan lingkungan dari program pemerintah yang disebut Bantuan Stimulan Perumahan Swadaya (BSPS) untuk masyarakat berpenghasilan rendah di Kota Baubau khususnya di Sub Lowulowu. Program BSPS memberikan perubahan dan dampak yang cukup baik. Program BSPS meningkatkan kualitas tempat tinggal warga dan meningkatkan kesejahteraan.

Kata Kunci: Program BSPS; Dampak Program; Dampak Sosial Ekonomi; Dampak Lingkungan; Rumah Tinggal
\end{abstract}

\section{PENDAHULUAN}

Pembangunan pada dasarnya bertujuan menciptakan kemakmuran dan mengurangi kemiskinan (Agustino, 2008). Kemiskinan merupakan ketidak mampuan seseorang untuk memenuhi kebutuhan makan dan bukan makan yang diukur dari pengeluaran. Kemiskinan merupakan masalah multidimensial, yang bukan hanya mencakup kondisi ekonomi tetapi juga sosial, budaya dan politik (Dewanta, 1999). Kemiskinan menjadi masalah utama yang terjadi di setiap wilayah, termasuk Kota Baubau. Angka kemiskinan yang masih tinggi menunjukkan program pengentasan kemiskinan belum mencapi hasil yang optimal. Hal ini dapat disebabkan oleh peningkatan pertumbuhan ekonomi yang tidak disertai dengan pemerataan terhadap sumber daya ekonomi sehingga pembangunan yang dijalankan belum mampu menekan angka

\footnotetext{
${ }^{1}$ Universitas Dayanu Ikhsanuddin, email: kuflia@gmail.com
} 
kemiskinan secara optimal (Damsar, 2009).

Pentingnya pemberantasan kemiskinan ditunjukkan salah satunya dengan tujuan SDGs (sustainable development goals) yang pertama dan kedua yaitu pemberantasan kemiskinan dan kelaparan. Berdasarkan data indikator kesejahteraan rakyak Kota Baubau tahun 2017 menunjukkan bahwa jumlah penduduk miskin di Kota Baubau mengalami pernurunan selama periode 2013-2017. Tahun 2013 jumlah penduduk miskin sebesar 15,1 ribu jiwa atau $10,11 \%$ dari jumlah seluruh penduduk di Kota Baubau pada tahun tersebut. Pemerintah terus berupaya menekan angka kemiskinan dan sampai pada tahun 2014 jumlah penduduk miskin terus berkurang menjadi 14,1 ribu atau $9,25 \%$ dari jumlah penduduk tahun 2014. Tahun 2015 tercatat jumlah penduduk miskin menurun menjadi 14,29 ribu jiwa atau 9,24\% dari jumlah penduduk pada tahun 2015. Jumlah penduduk miskin kembali turun pada tahun 2016 menjadi 13,87 ribu jiwa atau $8,79 \%$ dari total penduduk pada tahun 2016. Untuk lebih jelasnya dapat dilihat ta Tabel 1

Tabel 1. Garis Kemiskinan dan Penduduk di Kota Baubau, 2012-2017

\begin{tabular}{cccc}
\hline \multirow{2}{*}{ Tahun } & \multirow{2}{*}{$\begin{array}{c}\text { Garis } \\
\text { Kemiskinan }\end{array}$} & \multicolumn{2}{c}{ Penduduk Miskin } \\
\cline { 3 - 4 } & & Jumlah(ribu) & Persentase \\
\hline 2013 & 259.302 & 15,10 & 10.11 \\
\hline 2014 & 258.075 & 14,10 & 9,25 \\
\hline 2015 & 274.066 & 14,27 & 9,24 \\
\hline 2016 & 291.873 & 13,86 & 8,81 \\
\hline 2017 & 297.991 & 13,55 & 8,39 \\
\hline
\end{tabular}

Sumber : Survei Sosial Ekonomi Nasional

Berdasarkan Undang-Undang Nomor 1 Tahun 2011 Tentang Perumahan dan Kawasan
Permukiman bahwa pemerintah wajib memenuhi kebutuhan rumah bagi Masyarakat Berpenghasilan Rendah (MBR). Berikut disajikan jumlah masyarakat berpenghasilan rendah (MBR) di Kota Baubau sebagai kelompok sasaran dalam pemenuhan kebutuhan rumah seperti pada Tabel 2

Tabel 2. Jumlah Rumah Tangga MBR dan Non MBR di Kota Baubau Tahun 2017

\begin{tabular}{|c|c|c|c|c|}
\hline \multirow{2}{*}{$\begin{array}{l}\text { No } \\
\text { (1) }\end{array}$} & \multirow{2}{*}{$\begin{array}{c}\text { Kecamatan/ } \\
\text { Kelurahan } \\
\text { (2) }\end{array}$} & \multirow{2}{*}{$\begin{array}{c}\text { Jumlah Kepala } \\
\text { Rumah Tangga } \\
\text { (3) }\end{array}$} & \multicolumn{2}{|c|}{$\begin{array}{l}\text { Status Rumah } \\
\text { Tangga }\end{array}$} \\
\hline & & & $\begin{array}{l}\text { MBR } \\
\text { (4) }\end{array}$ & $\begin{array}{c}\text { Non MBR } \\
\text { (5) }\end{array}$ \\
\hline \multirow[t]{7}{*}{1.} & Kec. Betoambari & & & \\
\hline & Lipu & 997 & 817 & 180 \\
\hline & Katobengke & 1223 & 803 & 420 \\
\hline & Sulaa & 372 & 226 & 146 \\
\hline & Waborobo & 231 & 212 & 19 \\
\hline & Labalawa & 214 & 194 & 20 \\
\hline & Jumlah & 3.037 & 2.252 & 758 \\
\hline \multirow[t]{7}{*}{2.} & Kec. Murhum & & & \\
\hline & Baadia & 450 & 355 & 95 \\
\hline & Melai & 319 & 120 & 199 \\
\hline & Lamangga & 781 & 314 & 467 \\
\hline & Wajo & 512 & 177 & 335 \\
\hline & Tanganapada & 621 & 209 & 412 \\
\hline & Jumlah & 2.683 & 1.175 & 1.508 \\
\hline \multirow[t]{8}{*}{3.} & Kec. Batupoaro & & & \\
\hline & Bone-Bone & 910 & 571 & 339 \\
\hline & Kaobula & 339 & 206 & 133 \\
\hline & Tarafu & 890 & 391 & 499 \\
\hline & Wameo & 856 & 511 & 345 \\
\hline & Nganganaumala & 532 & 355 & 177 \\
\hline & Lanto & 705 & 346 & 359 \\
\hline & Jumlah & 4.232 & 2.380 & 1.852 \\
\hline \multirow[t]{9}{*}{4.} & Kec. Wolio & & & \\
\hline & Bataraguru & 1290 & 828 & 462 \\
\hline & Bukit Wolio Indah & 807 & 406 & 401 \\
\hline & Batulo & 765 & 208 & 557 \\
\hline & Kadolokatapi & 650 & 548 & 102 \\
\hline & Tomba & 569 & 283 & 286 \\
\hline & Wale & 289 & 61 & 228 \\
\hline & Wangkanapi & 555 & 355 & 200 \\
\hline & Jumlah & 4925 & 2.689 & 2.236 \\
\hline \multirow[t]{6}{*}{5.} & Kec. Sorawolio & & & \\
\hline & Bugi & 283 & 219 & 64 \\
\hline & Gonda Baru & 371 & 344 & 27 \\
\hline & Kaisabu Baru & 391 & 307 & 84 \\
\hline & Karya Baru & 343 & 295 & 48 \\
\hline & Jumlah & 1.388 & 1.165 & 223 \\
\hline \multirow[t]{8}{*}{6.} & Kec. Kokalukuna & & & \\
\hline & Kadolo & 544 & 285 & 259 \\
\hline & Kadolomoko & 838 & 475 & 363 \\
\hline & Lakologuo & 426 & 347 & 79 \\
\hline & Liwuto & 426 & 336 & 90 \\
\hline & Sukanayo & 451 & 288 & 163 \\
\hline & Waruruma & 674 & 423 & 251 \\
\hline & Jumlah & 3.359 & 2.154 & 1.205 \\
\hline
\end{tabular}




\begin{tabular}{lccr} 
7. Kec. Lea-Lea & & & \\
Kalia-Lia & 288 & 282 & 6 \\
Kantalai & 168 & 154 & 14 \\
Kolese & 217 & 202 & 15 \\
Lowu-Lowu & 402 & 293 & 109 \\
Ngkari-Ngkari & 549 & 257 & 292 \\
$\quad$ Palabusa & 395 & 355 & 40 \\
$\quad$ Jumlah & 2019 & 1.543 & 476 \\
Kec. Bungi & & 189 & 34 \\
$\quad$ Kampeonaho & 223 & 269 & 61 \\
$\quad$ Lia buku & 330 & 106 & 56 \\
$\quad$ Tampuna & 162 & 210 & 106 \\
$\quad$ Waliabuku & 316 & $\mathbf{7 7 4}$ & $\mathbf{2 5 7}$ \\
$\quad$ Jumlah & 1.031 & $\mathbf{1 4 . 1 3 2}$ & $\mathbf{8 . 5 4 2}$ \\
\hline Sub - Total & \multicolumn{3}{c}{$\mathbf{2 2 . 6 7 4 ^ { * }}$} \\
\hline Jumlah TOTAL & \multicolumn{3}{c}{$\mathbf{3 8 \%}$} \\
\hline Persentase & \multicolumn{3}{c}{} \\
\hline
\end{tabular}

Sumber: Baseline KOTAKU 2017

*Jumlah Rumah Tangga dalam Data ini tidak sesuai dengan data jumlah rumah tangga tahun 2017 di Data BPS Baubau Dalam Angka 2018 yang berjumlah 34.773, sehingga terjadi perbedaan sekitar 12.099 Rumah Tangga.

Berdasarkan Tabel 2 dapat dilihat bahwa presentase penduduk dengan status Masyarakat Berpenghasilan Rendah (MBR) mencapai 62\% dari total jumlah rumah tangga di Kota Baubau.

Tabel 3. Jumlah Penduduk dan Laju Pertumbuhan Penduduk di Kota Baubau, 2017

\begin{tabular}{lccccc}
\hline \multirow{2}{*}{ Kecamatan } & \multicolumn{3}{c}{ Jumlah Penduduk } & \multicolumn{3}{c}{$\begin{array}{c}\text { Laju Pertumbuhan Penduduk } \\
\text { Per Tahun }\end{array}$} \\
& $\mathbf{2 0 1 0}$ & $\mathbf{2 0 1 6}$ & $\mathbf{2 0 1 7}$ & $\mathbf{2 0 1 0 - \mathbf { 2 0 1 6 }}$ & $\mathbf{2 0 1 0 - \mathbf { 2 0 1 7 }}$ \\
\hline Betoambari & 16.283 & 18.844 & 19.381 & 2,43 & 2,56 \\
Murhum & 19.261 & 22.275 & 22.918 & 2,42 & 2,51 \\
Batupoaro & 25.889 & 29.941 & 30.802 & 2,42 & 2,51 \\
Wolio & 37.974 & 43.782 & 45.008 & 2,37 & 2,46 \\
Kokalukuna & 16.736 & 19.342 & 19.891 & 2,41 & 2,50 \\
Sorawolio & 7.112 & 8.195 & 8.426 & 2,36 & 2,45 \\
Bungi & 7.096 & 8.210 & 8.452 & 2,43 & 2,53 \\
Lea-Lea & 6.630 & 7.682 & 7.902 & 2,45 & 2,54 \\
\hline Baubau & $\mathbf{1 3 6 . 9 8 1}$ & $\mathbf{1 5 8 . 2 7 1}$ & $\mathbf{1 6 2 . 7 8 0}$ & $\mathbf{2 , 4 1}$ & $\mathbf{2 , 5 0}$ \\
\hline
\end{tabular}

Sumber : Proyeksi Penduduk 2010 2035

Memang upaya-upaya untuk menanggulangi masalah kemiskinan telah dicanangkan oleh Pemerintah Kota Baubau dengan membuat kebijakan-kebijakan yang pro warga miskin namun problem kemiskinan tetap ada. Ada beberapa strategi pembangunan yang telah dilakukan dengan maksud mengurangi tingkat kemiskinan (Fatchan, 2004). Pertama, mendorong pertumbuhan ekonomi daerah dengan cara menyelenggarakan berbagai program Inpres. Kedua, mempermudah lapisan sosial miskin untuk memperoleh akses pendidikan, kesehatan, keluarga berencana, air bersih, sanitasi dan lainlain. Ketiga, pembangunan infrastruktur ekonomi pada tiap kelurahan.

Upaya untuk menanggulangi kemiskinan juga dilakukan oleh Pemerintah Kota Baubau. Terbukti dengan adanya program-progam yang dicanangkan Pemerintah Kota Baubau seperti program Jamkesmas, raskin, program bedah rumah, dan sebagainya. Program yang menjadi unggulan bagi Kota Baubau adalah program bedah rumah dengan pelaksana Dinas Perumahan dan Kawasan Permukiman.

Program bedah rumah merupakan salah satu program dari pemerintah dalam upaya untuk memberikan perlindungan pada keluarga miskin guna meningkatkan tingkat kesejahteraan keluarga miskin tersebut. Program ini dilaksanakan dalam bentuk pemberian bantuan bahan bangunan beserta tukang dan tenaga teknisi untuk membangun atau merenovasi rumah yang tidak layak huni dan tidak memenuhi syarat kesehatan menjadi rumah yang layak huni. Pelaksanaan program bedah rumah di Kota Baubau telah selesai dilaksanakan pada tahun 2019. Kriteria yang digunakan sebagai persyaratan ialah (1) warga tersebut termasuk ke dalam warga miskin sekali, (2) rumah berada di wilayah Kota Baubau, (3) rumah non permanen, (4) rusak berat, (5) berdiri di atas tanah hak milik sendiri (dibuktikan dengan Surat 
kepemilikan/sertifikat milik/petok D maupun hibah, (6) lantai rumah berupa tanah, (7) taraf hidup rendah dengan penghasilan paspasan, (8) data-data dasar dari masing-masing kelurahan, yang sudah diketahui RT, RW, dan Lurah (KTP, KSK).

Bantuan Stimulan Perumahan Swadaya ini adalah fasilitas pemerintah berupa bantuan sosial kepada Masyarakat Berpenghasilan Rendah (MBR). Bantuan yang diberikan berupa kegiatan memperbaiki komponen rumah/memperluas rumah untuk meningkatkan/memenuhi syarat rumah layak huni. Kota Baubau menjadi salah satu kota yang mendapatkan bantuan tersebut berdasarkan atas Surat Edaran Nomor 02 Tahun 2019 Perihal Pelaksanaan Tugas Fasilitas Bantuan Stimulan Perumahan Swadaya oleh Pemerintah Kabupaten/Kota yang ditujukan untuk Bupati dan Walikota di seluruh Indonesia. Bantuan Stimulan Perumahan Swadaya di Kota Baubau dilaksanakan oleh Dinas Perumahan dan Kawasan Permukiman sesuai dengan dan dana yang digunakan adalah dana berasal dari Anggaran Pendapatan dan Belanja Negara (APBN).

Dari 43 kelurahan yang ada di Kota Baubau, sebanyak 39 kelurahan mengajukan daftar rumah tidak layak huni di wilayahnya, sedangkan 4 kelurahan tidak mengajukan dengan alasan sudah tidak ada rumah tidak layak huni di wilayahnya.. Berikut ini data awal rumah tidak layak huni dari masing-masing kelurahan pada Kecamatan Lealea yang didapat dari
Dinas Perumahan dan Kawasan Permukiman.

Tabel 4. Jumlah Rumah Berdasarkan Aspek Kelayakan Hunian di Kecamatan Lea-Lea

\begin{tabular}{llccc}
\hline No & Kelurahan & $\begin{array}{c}\text { Jumlah } \\
\text { rumah (unit) }\end{array}$ & $\begin{array}{c}\text { Layak huni } \\
\text { (unit) }\end{array}$ & $\begin{array}{c}\text { Tidak layak huni } \\
\text { (unit) }\end{array}$ \\
\hline 1. & Kolese & 298 & 114 & 184 \\
\hline 2. & Lowu-Lowu & 498 & 183 & 315 \\
\hline 3. & Kalia-lia & 279 & 112 & 167 \\
\hline 4. & Kantalai & 214 & 126 & 88 \\
\hline 5. & Palabusa & 402 & 194 & 208 \\
\hline & Lea-Lea & $\mathbf{1 . 6 9 1}$ & $\mathbf{7 2 9}$ & $\mathbf{9 6 2}$ \\
\hline
\end{tabular}

Sumber: Baseline Data KOTAKU Tahun 2017, Siurvey Primer 2018 dan Basis data Dinas PKP Kota Baubau tahun 2018

Lowulowu dengan jumlah 962 unit. Sedangkan Kelurahan Lowulowu memiliki jumlah rumah tidak layak huni tertinggi di Kecamatan Lealea dengan jumlah 315 unit lebih tinggi dari Kelurahan Oalabusa dengan jumlah 208 unit. Oleh karena itu, peneliti ingin melihat dampak Program BSPS di Kelurahan Lowulowu, dengan alasan Kelurahan Lowulowu memiliki warga dengan angka rumah tidak layak huninya paling banyak. Kelurahan Lowulowu berada di Kecamatan Lealea Kota Baubau..

\section{METODE PENELITIAN}

Pendekatan participatory digunakan untuk memperoleh urutan prioritas dan masuk-masukan dari berbagai stakholders untuk melengkapi data yang sudah dihasilkan (Miles \& Heberman, 1992). Selain melalui penyebaran kuisioner dan wawancara, pendekatan partcipatory ini juga dilakukan dengan melalui rembuk warga untuk mengkaji lebih lanjut hasil analisis yang dibuat. 


\section{HASIL DAN PEMBAHASAN}

Kelurahan

Lowulowu

Kecamatan Lealea termasuk salah satu kawasan kumuh sesuai dengan SK Kumuh Walikota 2015 seluas 2,18 hektar yang berada di kawasan pesisir Kota Baubau juga termasuk cluster kawasan kumuh kampung nelayan. Luas kawasan kumuh setelah di verifikasi lapangan menjadi berkurang seluas 1,68 hektar. Kondisi lingkungan hunian permukiman di Kelurahan Lowulowu sebelum adanya bantuan Program Bantuan Stimulan Perumahan Swadaya (BSPS) dinilai buruk baik dari segi kesehatan maupun sosial masyarakatnya. Pemerintah Kota Baubau berupaya untuk mengurangi adanya kawasan kumuh dengan berbagai program bantuan baik yang dicanagkan di daerah maupun pemerintah pusat. Program BSPS merupakan salah satu program untuk peningkatan kualitas hunian masyarakat pada masyarakat berpenghasilan rendah. Untuk itu perlu didukung bukan saja dari pemerintah daerah tetapi juga masyarakat pula bersama-sama mensukseskan program tersebut agar kondisi lingkungan hunian khususnya bangunan lebih baik lagi kualitasnya sehingga akan mendapatkan rumah yang layak huni.

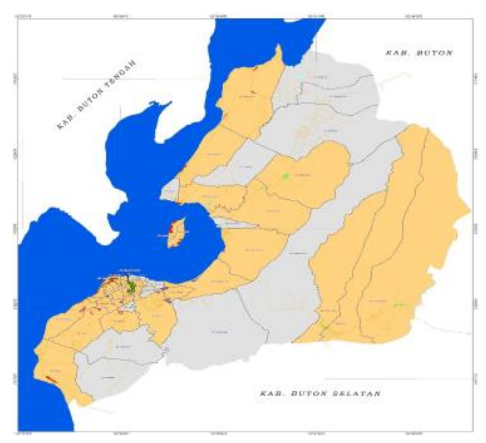

Gambar 1. Kawasan Rumah Huni Kabupaten Buton Selatan

Untuk mewujudkan rumah yang layak huni yang didukung dengan prasarana, sarana, dan utilitas umum sehingga menjadikan perumahan yang sehat, aman, serasi, dan teratur serta berkelanjutan, perlu didukung dengan bantuan stimulan perumahan swadaya dengan mengoptimalkan pengaturan bantuan pembangunan rumah bagi masyarakat berpenghasilan rendah yang berupa stimulan rumah swadaya. Bantuan Stimulan Perumahan Swadaya yang selanjutnya disingkat BSPS adalah bantuan pemerintah berupa stimulan bagi masyarakat berpenghasilan rendah untuk meningkatkan keswadayaan dalam pembangunan/ peningkatan kualitas rumah beserta prasarana, sarana, dan utilitas umum. Masyarakat Berpenghasilan Rendah yang selanjutnya disingkat MBR adalah masyarakat yang mempunyai keterbatasan daya beli sehingga perlu mendapat dukungan pemerintah untuk memperoleh rumah yang layak huni. Prasarana, Sarana, dan Utilitas Umum adalah kelengkapan dasar fisik, fasilitas dan kelengkapan penunjang yang dibutuhkan agar perumahan dapat berfungsi secara sehat, aman, dan nyaman.

Persyaratan teknis penerima bantuan Program Bantuan Stimulan

Perumahan Swadaya (BSPS) yakni :

1. WNI yg sudah berkeluarga;

2. Memiliki atau menguasai tanah;

3. Belum pernah memperoleh BRS atau program sejenis;

4. MBR dengan penghasilan paling banyak sebesar UMP; 
5. Bersedia berswadaya dan membentuk kelompok.

6. Memiliki rumah dalam kondisi tidak layak huni. Persyaratan Penerima Bantuan :

Swadaya yang berkaitan dengan BSPS adaya swadaya masyarakat untuk menciptakan rumah layak huni(RLH). Swadaya yang ada dalam BSPS adalah sebagai berikut :

- Uang

- Bahan bangunan

- Tenaga kerja Sumber dari swadaya

- Keluarga Inti

- Keluarga Besar (Extended Family)

- Lingkungan

Rumah yanga di bangun dengan swadaya ini di sebut dengan rumah swadaya, yaitu ruamah yang di bangun atas prakarsa dan upaya masyarakat . Perumahan Swadaya adalah kumpulan rumah swadaya sebagai bagian dari permukiman baik perkotaan maupun perdesaan yang dilengkapi dengan PSU.(Pemen PUPR 7/PRT/M/2018 tentang BSPS)

Untuk memperbaiki rumah tidak layak huni menjadi layak huni dengan memenuhi persyaratan:

a. keselamatan bangunan;

b. kecukupan minimum luas bangunan, dan/atau;

c. kesehatan penghuni;

Keselamatan

bangunan merupakan kondisi dengan tingkat kerusakan :
a. rusak ringan;
b. rusak sedang; atau
c. rusak berat.

Ditinjau

dari

aspek

ketidakteraturan bangunan, Kawasan Kumuh Kampung Nelayan memiliki permukiman yang kurang teratur, terlihat dari jumlah unit hunian yang tidak teratur sebesar 332 unit hunian atau sebesar $50 \%$ dari total keseluruhan bangunan dalam Kawasan Kumuh Pesisir dan Kampung Nelayan. Sementara dari aspek kepadatan bangunan, semua bangunan di kawasan ini memiliki kepadatan bangunan sesuai dengan ketentuan, yaitu di bawah 200 unit/Ha. Dan dari segi persyaratan teknis bangunan, $49 \%$ bangunan pada lokasi tidak memenuhi persyaratan teknis.

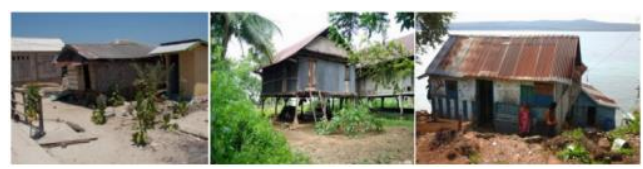

Gambar 1. Kondisi Bangunan di Kawasan Kampung Nelayan

Berdasarkan hasil survey yang dilakukan, panjang jalan lingkungan dengan lebar $\geq 1,5 \mathrm{~m}$ pada kawasan Kumuh Kampung Nelayan dengan material perkerasan dan mengalami kerusakan sepanjang 3.296 meter dengan jangkauan jaringan jalan lingkungan yang tidak layak sebesar $28 \%$ atau sepanjang 2.768 meter.
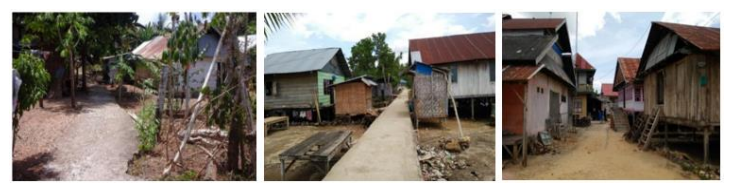

Gambar 2. Kondisi Jalan Lingkungan di Kawasan Kampung Nelayan

Kondisi drainase yang tidak berfungsi baik atau drainase dengan kualitas rusak di Kawasan Kumuh Pesisir dan Kampung Nelayan memiliki panjang 234 meter atau 17\% dengan presentasi kawasan 
permukiman yang mengalami genangan air/banjir yang disebabkan oleh kondisi drainase yang buruk yaitu sebesar $33 \%$ atau seluas 10,7 ha

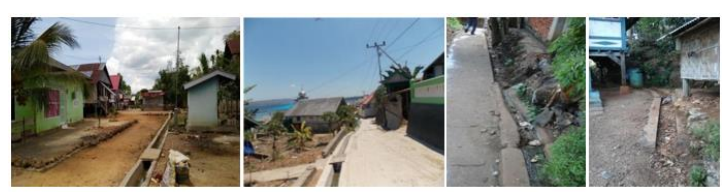

Gambar 3. Kondisi Drainase di Kawasan Kampung Nelayan

Ditinjau dari aspek pelayanan air bersih, 28\% (183 unit) rumah tangga pada kawasan Kumuh Pesisir dan Kampung Nelayan tidak terlayani Sarana Air Minum untuk minum, mandi dan cuci dengan sitem perpipaan dan nonperpipaan terlindungi yang layak. Sedangkan 61\% atau 404 unit Rumah tangga yang belum terpenuhi kebutuhan air minum untuk minum, mandi dan cuci dengan jumlah minimal 60 liter/orang/hari.

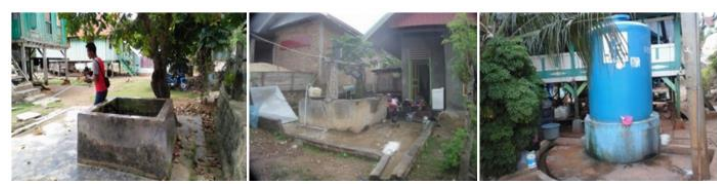

Gambar 4. Kondisi Air Minum di Kawasan Kampung Nelayan

Ditinjau dari aspek pengelolaan air limbah, 37\% (244 unit) rumah tangga belum memiliki akses terhadap sistem sanitasi baik berupa jamban keluarga maupun jamban bersama, dengan jumlah jamban keluarga/jamban bersama yang tidak memenuhi persyaratan teknis berupa sistem kloset leher angsa yang terhubung dengan septic tank sebesar 195 unit atau sebesar 30 persen.

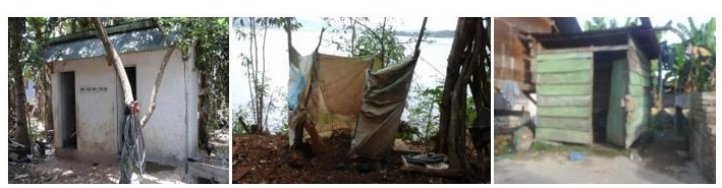

Gambar 5. Kondisi Air Limbah di Kawasan Kampung Nelayan
Ditinjau dari sistem pengelolaan persampahan, Kawasan Kumuh Kampung Nelayan belum memiliki sistem pengelolaan persampahan yang baik, terlihat dari jumlah sampah domestik rumah tangga yang tidak terangkut ke TPS/TPA minimal 2 kali seminggu berasal dari 628 unit rumah tangga atau sebesar $95 \%$ dari total jumlah sampah domestik rumah tangga yang ada dalam Kawasan Kumuh Pesisir dan Kampung Nelayan

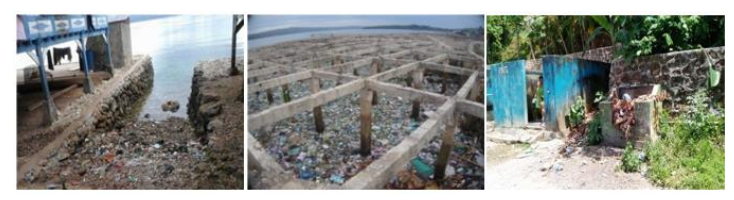

Gambar 6. Kondisi Persamphan di Kawasan Kampung Nelayan

Dengan adanya bantuan program peningkatan kualitas bangunan atau hunian yakni Program Bantuan Stimulan Perumahan Swadaya (BSPS) memberikan dampak atau pengaruh terhadap kualitas bangunan khususnya juga lingkungan hunian di kawasan dimaksud. Selain itu juga berpengaruh terhadap sosial ekonomi masyarakat yang mendapatkan bantuan program tersebut yakni tempat tinggal yang lebih layak huni.

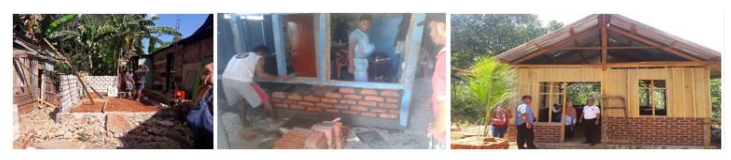

Gambar 7. Pra dan Pasca Konstruksi Bangunan Program BSPS

Perubahan-perubahan yang terjadi pada masyarakat bisa mengenai nilai-nilai sosial, norma-norma sosial, pola-pola perilaku organisasi, susunan lembaga kemasyarakatan, lapisanlapisan dalam masyarakat, kekuasaan dan wewenang, serta interaksi social (Dunn, 1999). Interakasi sosial 
merupakan hubungan-hubungan sosial yang dinamis yang menyangkut hubungan antara orang-orang perorangan dengan kelompok manusia. Interaksi sosial adala suatu hubungan antara individu atau lebih, dimana kelakuan individu yang satu mempengaruhi, mengubah atau memperbaiki kelakuan individu lain atau sebaliknya. Pengaturan interaksi sosial diantara para anggota terjadi karena commitment mereka terhadap norma-norma sosial yang menghasilkan daya untuk mengatasi perbedaanperbedaan pendapat dan kepentingan diantara mereka (Soekanto,1994). Interaksi sosial yang terjadi dalam kehidupan masyarakat menghasilkan suatu hasil yang mana sebuah interaksi sosial yang terjadi dalam kehidupan masyarakat akan diikuti dengan tindakan sosial (social action). Dengan komunikasi ide-ide baru dan informasi baru akan merubah penilaian masyarakat tentang berbagai hal yang selanjutnya akan mengubah ke arah tindakan yang baru.

Lingkungan adalah keadaan
sekitar yang mempengaruhi
perkembangan dan tingkah laku makhluk hidup. Kondisi lingkungan yang baik akan membawa dampak yang baik pula dalam kelangsungan hidup sehari-hari. Lingkungan yang tidak sehat ini juga akan mempengaruhi kehidupan sehari-hari. Misalnya lingkungan yang tidak sehat akan menimbulkan berbagai macam penyakit. Lantai rumah yang hanya beralaskan tanah akan menimbulkan debu yang bertebaran yang akan mengganggu pernafasan. Oleh karena itu melalu program BSPS ini secara tidak langsung akan memperbaiki kualitas hidup dan menghindarkan dari berbagai macam penyakit

\section{KESIMPULAN}

Kondisi sosial ekonomi masyarakat, khususnya masyarakat berpenghasilan rendah (MBR) cenderung memicu munculnya hunian kumuh di perkotaan.Program pemerintah yang dicanangkan dalam mengurangi tingkat kekumuhan dan meningkatkan kualitas bangunan dan hunian sangat berpengaruh terhadap masyarakat penerima bantuan yakni masyarakat berpenghasilan rendah sehingga menghasilkan hunian yang layak huni. Untuk mewujudkan rumah yang layak huni yang didukung dengan prasarana, sarana, dan utilitas umum sehingga menjadikan perumahan yang sehat, aman, serasi, dan teratur serta berkelanjutan, perlu didukung dengan bantuan stimulan perumahan swadaya; Sebelum masyarakat penerima mendapatkan bantuan program peningkatan kualitas hunian yakni Bantuan Stimulan Perumahan Swadaya terlihat kondisi bangunan butuk dan tidak layak huni. Program bantuan BSPS ini juga akan mengurangi luas kawasan kumuh di Kelurahan Lowulowu Kecamatan Lealea Kota Baubau. Masyarakat sangat antusias menerima bantuan program BSPS ini dengan cara bergotong royong membangun rumah secara swadaya. Pemberdayaan masyarakat di Kelurahan Lowulowu khususnya dilakukan melalui media edukasi dan penyuluhan serta pendampingan dan pelayanan informasi yang sesuai dengan standar dan norma yang berlaku, selain itu Pencegahan terhadap tumbuhnya dan berkembangnya permukiman Kumuh baru dilaksanakan melalui kegiatan 
pengawasan dan pengendalian kawasan. Peremajaan dilakukan dalam upaya mewujudkan kondisi rumah, permukiman, dan lingkungan hunian yang lebih baik dengan tujuan untuk melindungi keselamatan dan keamanan penghuni dan masyarakat sekitar. Untuk meremajakan suatu kawasan, terlebih dahulu perlu menyediakan tempat inggal bagi masyarakat yang terkena dampak. Peremajaan harus menghasilkan rumah, dan permukiman dengan kualitas yang lebih baik dari sebelumnya.

\section{DAFTAR PUSTAKA}

Agustino, L. (2008). Dasar-dasar Kebijakan Publik. Bandung: Alfabeta.

Damsar. (2009). Pengantar Sosiologi Ekonomi. Jakarta: Kencana.

Dewanta, A, S. (1999). Kemiskinan dan Kesenjangan di Indonesia. Yogyakarta: Aditya Media.

Dunn, W, N. (1999). Pengantar Analisis Kebijakan Publik. Yogyakarta: Gajah Mada University Press.

Fatchan, A. (2004). Teori-teori Perubahan Sosial: Dalam Kajian Perspektif dan Empirik Pada Proses Pembangunan Pertanian. Surabaya: Lutfansah Mediatama.

Miles, M, \& Huberman, M. (1992). Analisis Data Kualitatif. Jakarta: Penerbit Universitas Indonesia.

Soekanto, S. (1994). Sosiologi: Suatu Pengantar. Jakarta Utara: RajaGrafindo Persada.
Triana, R, W. (2011). Implementasi dan Evaluasi Kebijakan Publik. Surabaya: PT Revka Petra Media. 